\title{
Stress, psychosocial factors and the New Zealand forest industry workforce: Seeing past the risk of harm to the potential for individual and organisational wellbeing
}

\author{
Trevor Best*, Rien Visser and David Conradson \\ University of Canterbury, Private Bag 4800, Christchurch 8140, New Zealand \\ *Corresponding author: trevor.best@pg.canterbury.ac.nz \\ (Received for publication 21 January 2020; accepted in revised form 7 April 2021)
}

\begin{abstract}
Background: There is clear evidence that stress is having an impact on the health and wellbeing of the forest industry workforce in Aotearoa New Zealand. While this has legal ramifications under the national health and safety legislation, international research also shows that harm to mental health invariably leads to reductions in work force productivity and business profitability. The reverse is also true: improved mental wellbeing can lead to greater worker engagement and commitment, which in turn increases productivity and profitability. Although these relationships are well substantiated, managers and leaders in the forest industry may not be aware of either the existence of a workplace stress problem or of its impact.

Methods: A critical review is undertaken of stress and psychosocial hazards research within the international forest industry or similar industries (e.g. construction), with particular attention given to the explanation of psychosocial hazards.

Results: International research on the forest industry largely confirms what we know about harmful aspects of job content and workplace conditions. However, it is argued that the focus within this research on job content and immediate workplace conditions obscures the impact of the wider social context. This limits the potential of management to move beyond seeing psychosocial factors simply as risks to be minimised at the workplace level. Bringing an ecological perspective to the analysis of forestry workplaces makes it easier to identify the elements of forest management practice that may contribute to stress within the workforce. It also becomes easier to identify the interactions between family, community and workplaces that may either exacerbate or reduce workforce stress.

Conclusions: This paper highlights particular opportunities for reducing stress and enhancing wellbeing within the New Zealand forest industry workforce. It suggests that the psychosocial conditions that contribute to mental ill-health can be reconfigured to promote mental health, with wellbeing benefits that extend beyond the workplace. Psychosocial demands on a person can be motivating as long as the person has the resources to meet the challenge. Successful stewardship of the psychosocial environment at the forest management level is thus an opportunity to increase value to both investors and other stakeholders.
\end{abstract}

Keywords: work-related stress, psychosocial hazards, forest industry workforce, ecological perspective

\section{Introduction}

At the core of the constitution of the World Health Organisation is the notion that health is a human right that goes beyond the absence of harm to include physical, mental and social wellbeing (World Health Organisation 2019). In the psychosocial domain, health can be understood as emerging from the relations between our physical and mental capabilities and the social environments in which our lives unfold (Woodward 2015). Work therefore has the potential to enhance a person's sense of wellbeing (Modini et al. 2016). Unlike physical hazards, where wellbeing can be enhanced by the elimination of the hazard, psychosocial factors relating to the nature of work and the demands it places on the worker exist along a continuum from causing harm to promoting wellbeing (Bentley et al. 2019; Leka 
et al. 2015). Yet rather than managing those psychosocial factors to promote worker wellbeing (Leka et al. 2015), the occupational health and safety frameworks in most developed countries seek to prevent harm by eliminating or minimising the risks to worker health represented by hazardous psychosocial conditions (Chirico et al. 2019). Recent changes in New Zealand's health and safety legislation are a good example of the limitations of this approach. The Health and Safety at Work Act 2015 contains a clear expectation that the work-related risks to a person's mental health should be managed by the people in charge of that work or workplace (Health and Safety at Work Act 2015). In the interpretations (section 16) of the Act, the definition of a hazard includes behaviour that has the potential to harm, "whether or not that behaviour results from physical or mental fatigue, drugs, alcohol, traumatic shock, or another temporary condition that affects a person's behaviour". The understanding of "health" in the Act includes both mental and physical health. However, managing workplace factors that impact psychosocial health through a framework of psychosocial hazards may obscure the opportunity to enhance both individual and organisational health represented by those factors. Health should be addressed as something more than harm elimination or reduction (Leka et al. 2015).

Designing workplaces and work processes in ways that go beyond harm elimination and reduction can improve a worker's quality of life and enhance productivity and sustainability. Making such interventions can be a challenge when the workforce is largely employed through service contracts, however, as is the case with the New Zealand forest industry. While the direct terms and conditions of the employment relationship are set by the contractor/employer, the scope of those conditions is largely controlled by the agreement between the contractor and the forest owner. The organisation of the work and the workplace is therefore not totally within the control of the employer. However, the Health and Safety at Work Act 2015 places the responsibility for the primary duty of care onto a "Person conducting a business or undertaking" (PCBU). This means that the obligation for managing the risk of a negative health outcome arising from mental distress sits with whoever creates that risk, regardless of where in the process of work that risk arises (and irrespective of the nature of the employment relationship between the PCBU and the worker who suffers harm).

This obligation to manage risk is more than just a legal and economic matter. The principles behind the International Labour Organisation's health and safety standards are not just that work should take place in a safe and healthy working environment, but also that conditions of work should be consistent with workers' wellbeing and human dignity. Work should offer real possibilities for personal achievement, self-fulfilment and service to society (Forastieri 2016). Although the legal challenge for the forest industry is to design workplaces and processes that reduce mental harm across business boundaries, this expectation also presents a moral and economic opportunity. By focusing on wellbeing rather than harm reduction, the industry could positively impact both workers' quality of life and reap the potentially significant financial benefits of a more loyal, engaged, and productive workforce.

What makes this challenging for forest owners and managers is that the feedback loops that could bring the impacts of mental distress to their attention are poorly developed. While noting signs of stress in the workforce, Lovelock and Houghton (2017) and Nielsen (2015b) both concluded that more work was needed to increase awareness of the full range of risks faced by forestry workers and the health impacts of those risks. Furthermore, the arm's length nature of their service agreements means that forest owners and managers do not have the direct relationship with worker health and safety that would enable awareness of stress and its impacts. Despite widespread annual physical health checks of workers by contractors, there is no consistent and centralised assessment process in operation within the industry (Forest Industry Safety Council 2018). The generally available investigation methods used to generate a learning feedback loop after an accident are unable to take psychosocial factors and any associated stress into account (Van Wassenhove \& Garbolino, 2008, as cited by Leka et al. 2015). Those charged with managing health and safety within the New Zealand forest industry could well be operating somewhat unaware of the potential impacts of stress in its various expressions on workers' wellbeing.

Against this backdrop, this paper examines the research on stress within the international forest industry workforce so as to identify opportunities for enhancing wellbeing amongst forest industry workers in New Zealand. It begins by reviewing how work-related stress and its risk factors are generally explained. It then considers what the extant research on work-related stress from the world's forest industries suggests about health impacts and psychosocial hazards within forestry. It finishes by questioning whether a focus on workplace psychosocial hazards is the most appropriate framework to address stress and wellbeing within the forest industry workforce in New Zealand. An alternative approach is presented, based on ecological systems theory, and some of the implications for potential interventions are noted.

\section{Explaining work-related stress}

Work-related stress has generated a large body of academic research that focuses primarily on how a person fits or does not fit into his or her work environment (Väänänen et al. 2014). In this framework, work-related stress is seen as psychological strain or a set of negative psychophysiological responses and reactions (Chirico et al. 2019) that occur either when the demands of the work environment exceed the capabilities and resources of the worker or when the needs of the worker cannot be supplied by the work environment (Dewe \& Cooper 2017; Forastieri 2016). Stress is thought to occur when that mismatch becomes chronic or unmanageable (Leka et al. 2015). Much research has sought to clarify the relationship between the work environment and the individual's body and 
mind through investigations of the impact of work place characteristics on particular unhelpful behaviours and psychological and somatic symptoms (Väänänen et al. 2014). Measuring both the psychosocial hazards and the symptoms has required the development of self-rating scales (Väänänen et al. 2014). This work has shown that chronic and unresolvable exposure to a number of work place characteristics can increase the likelihood that a proportion of the workforce will suffer a negative psychophysiological response as a result (Leka \& Jain 2010; Maslach \& Leiter 2016).

Both the New Zealand Workplace Barometer (Bentley et al. 2019) and the World Health Organisation review of psychosocial hazards at work (Leka \& Jain 2010) use the following definition of psychosocial hazards:

those aspects of work design and the organisation and management of work, and their social and environmental contexts, which have the potential for causing psychosocial or physical harm. (Cox et al. 2003, p. 195)

The World Health Organisation (2008) developed a summary of work-related psychosocial hazards (see Table 1) for the European Framework for Psychosocial Risk Management. The framework identifies ten psychosocial domains, each of which can be thought of as a potential source of work-related stress (Forastieri 2016). The domains are divided into two groups: work content (which includes psychosocial hazards related to the conditions, organisation and component tasks of the job), and work context (which includes psychosocial hazards related to workplace organisation) (Cox \& Griffiths, 2005, as cited by Forastieri 2016). The New Zealand Workplace Barometer is closely based on this EU framework, in that it incorporates all ten domains and adds workplace bullying to the domain of interpersonal relationships at work (Bentley et al. 2019). Given that the New Zealand Workplace Barometer lists forestry as one of the industries with the highest reported levels of bullying - with greater than $10 \%$ of respondents reported having been bullied - the addition of bullying is highly relevant to the industry. This is particularly the case as the definition of bullying used by the survey required the harassment to occur over a period of time and to involve one or more perpetrators (Bentley et al. 2019). The World Health Organisation (2008) point out that while bullying can be considered a psychosocial risk, it should also be regarded as a consequence of a poor psychosocial work environment. The implication of this perspective is that if an organisation mitigates the risks listed in Table 1, then the risk of bullying will also reduce.

The findings of other research overlap considerably with this framework, albeit with different emphases. In their review of two decades of research on burnout and its causes and outcomes, Maslach and Leiter (2016) pointed to six key domains of psychosocial hazards: workload, control, reward, community, fairness and values. Of these domains, the conceptualisation and

TABLE 1: Work-related psychosocial hazards

\begin{tabular}{ll}
\hline Psychosocial Hazard & Explanation \\
\hline \multirow{2}{*}{ Job content } & \multicolumn{1}{c}{ Work Content } \\
\cline { 2 - 2 } Workload and work pace & $\begin{array}{l}\text { Lack of variety or short work cycles, fragmented or meaningless work, underuse of } \\
\text { skills, high uncertainty, continuous exposure to people through work. } \\
\text { Work overload or underload, machine pacing, high levels of time pressure, continually } \\
\text { subject to deadlines. }\end{array}$ \\
Work schedule & $\begin{array}{l}\text { Shift working, night shifts, inflexible work schedules, unpredictable hours, long or } \\
\text { unsociable hours. }\end{array}$ \\
Environment and equipment & $\begin{array}{l}\text { Inadequate equipment availability, suitability or maintenance, poor environmental } \\
\text { conditions such as lack of space, poor lighting, excessive noise. }\end{array}$ \\
Control & $\begin{array}{l}\text { Low participation in decision making, lack of control over workload, pacing, shift } \\
\text { working. }\end{array}$ \\
\cline { 2 - 3 } $\begin{array}{l}\text { Organisational culture and } \\
\text { function }\end{array}$ & $\begin{array}{l}\text { Poor communication, low levels of support for problem solving and personal } \\
\text { development, lack of definition of, or agreement on, organisational objectives. } \\
\text { at work } \\
\text { Role in organisation }\end{array}$ \\
Career development & $\begin{array}{l}\text { Social or physical isolation, poor relationships with superiors or co-workers, } \\
\text { interpersonal conflict, lack of social support. } \\
\text { Role ambiguity, role conflict, and responsibility for people. }\end{array}$ \\
Home-work interface & $\begin{array}{l}\text { Career stagnation and uncertainty, under promotion or over promotion, poor pay, job } \\
\text { insecurity, low social value to work. } \\
\text { Conflicting demands of work and home, low support at home, dual career problems. }\end{array}$ \\
\hline
\end{tabular}

Source: (Cox et. al. 2000, as cited by Forastieri 2016) 
explanatory significance of workload, control and community are similar to the European Framework. In contrast, Maslach and Leiter (2016) place much greater emphasis on the role of rewards (financial, institutional or social), fairness (the extent to which decisions are perceived as being fair and equitable) and values (the alignment between the individual's values and those of the organisation they work for) in the development of burnout. Nevertheless, these differences may be quite important to the health and wellbeing of the various actors within the New Zealand forest industry. Issues such as whose interests are represented in the service contracts that form the basis for employment of the workforce and how those contracts distribute risk and reward will shape the perception of whether those agreements are seen as fair and equitable. Furthermore, with a workforce that is approximately 37\% Māori (Ministry for Primary Industries 2020) there is a significant potential for differences in world views between a substantial part of the workforce and the forest industry, creating mis-alignment in values (B. Hooper, personal communication, 13 August 2020).

Similarly, in a review of the epidemiological literature of work-related stress, Pfeffer (2018) points to ten workplace exposures that affect human health through stress. As with the psychosocial hazards associated with burnout, this perspective is largely the same as that used in the European Framework. However, there are key differences that are important in the context of the New Zealand forest industry. Job insecurity, whether for one's own job or that of colleagues, is much more prominent in Pfeffer's framework. This is something that could be considered important in an industry which employs most of its workforce on a contractual basis. Workers paid by piece rates or hourly rates are exposed to the risk of reduced hours or job loss resulting from contractual transgressions or downturns in the log market. Job insecurity is also highlighted as a key work-related psychosocial stressor by other authors (e.g. Dewe \& Cooper 2017). Furthermore, Pfeffer included access to health care as a significant stressor, reflecting the "US-centric" nature of the epidemiological literature. However, any industry reliant on a rurally located workforce in New Zealand should be cognisant of reduced access to health care for those who live outside the urban centres, a pattern which reflects health service restructuring between 1980 - 2001 and the consequential differences in all-cause mortality rates between urban and rural regions (Pearce et al. 2008).

The differences between these frameworks highlight the contextual nature of psychosocial hazards and the need for psychosocial risks within the New Zealand forest industry to be researched more thoroughly than is currently the case. However, there has been research undertaken within the forest industries of other countries that is relevant in the New Zealand context. This research, which highlights potential psychosocial hazards in the New Zealand forest industry and their impacts on health and wellbeing, is discussed in the next section.

\section{Evidence of health impacts of work-related stress in the forest industry}

Within the international forest industry, the study of known mental health conditions and their association with wellbeing and safety is centred on an 18 year prospective cohort study of workers at a Finnish based multinational forest industry company (Väänänen et al. 2008). This study assessed health and potential risk factors within the workforce, which included manual labourers and machine operators. Research based on data from this study has highlighted the association of burnout with negative health and safety outcomes. Burnout was assessed using the Maslach Burnout Inventory (MBI, Maslach, Jackson \& Leiter, 1996, as cited in Maslach \& Leiter 2016). This consists of three dimensions: overwhelming physical and emotional exhaustion arising from depleted emotional and physical resources with insufficient recovery (Maslach \& Leiter 2017); feelings of cynicism that reflect a detached attitude towards work and increasing disregard towards one's co-workers and clients (Toppinen-Tanner et al. 2002); and a reduced sense of accomplishment and effectiveness (Seidler et al. 2014). Assessments occurred at various times throughout the study period and could be correlated with a number of different health outcomes recorded by Finland's National Population Register Centre and the company itself (Väänänen et al. 2008).

The health outcomes explored over the life of this research program are significant to the New Zealand forest industry for a number of reasons: firstly, they involve a large number of participants (ranging from 3895 to 10062 employees) that are mostly men (greater than 76\%) involved in manual work or machine operation (greater than 62\%); and, secondly, burnout is correlated with clinically derived indicators of health (Väänänen et al. 2008). These are considered more reliable than self-report measures (Väänänen et al. 2014). The research facilitated by this program all points to burnout being associated with negative health outcomes. An increase in the MBI summary score of one unit was associated with a $35 \%$ increase in the risk of mortality among workers less than 45 years old (Ahola et al. 2010). Of the subscales, only exhaustion produced a statistically significant hazard ratio when adjusted for sociodemographic and baseline health factors. A similar study of the relationship between burnout and severe injuries by the same research group found a one unit increase in the burnout summary score to be related to a $10 \%$ increase in the risk of injury requiring hospitalisation or causing death (Ahola et al. 2013). Of the MBI subscales, emotional exhaustion was associated with a $9 \%$ increase in the risk of injury, while cynicism was related to a $10 \%$ increase. This suggests that having both energy and motivation to act safely is important to prevent workplace injury or death. Toppinen-Tanner et al. (2005) reported on burnout as an event prior to sickness absence for different medically certified causes of absence. They found that the MBI summary score was positively correlated with the risk of future medically certified absence (after adjustment for age, gender, 
occupation, and baseline absence). The increased risk of future illness was shown to include mental and behavioural disorders and diseases of the cardiovascular and musculoskeletal systems. Burnout predicted future hospital admissions for mental health and cardiovascular disorders among participants who had not suffered the disorder prior to the start of the study (Toppinen-Tanner et al. 2009). Although none of these studies defined a causal pathway between burnout and negative health outcomes, they do suggest that work-related stress conditions are associated with increased risk of injury, illness and early mortality within a male dominated, manual and machine operator workforce. Such research is relevant to the New Zealand forest industry.

Of concern, therefore, is that there are already indications that mental distress is having an impact on New Zealand forest industry workers. The New Zealand forest industry is part of an occupational group (Forestry and Farming) that comprises $6.8 \%$ of male suicide victims in New Zealand (Suicide Mortality Review Committee 2016). If that percentage still holds, increases in male suicide levels in New Zealand (Coronial Services 2020) suggest that deaths by suicide could have exceeded accidental workplace deaths for the farming and forestry occupational group in both 2018 and 2019. WorkSafe New Zealand's National Health and Safety Attitudes and Behaviours Survey (NHABS) also noted that "stressrelated or mental illness was more likely to be identified as a long-term health problem by workers who had personally experienced a serious harm incident $(22 \%$ compared with $12 \%$ of those who had not experienced an incident) or a near miss incident (19\% compared with 11\%)" (Nielsen 2015a, p. 68). The same survey found that $27 \%$ of employees and $36 \%$ of employers experienced a serious harm near miss or actual incident in the preceding 12 months (Nielsen 2015a). This is in line with international evidence that highlights (i) the interaction between exposure to actual and potential trauma and mental health disorders (Tehrani 2004) and, more specifically, (ii) the relationship between exposure to risks and hazards and mental distress (Nahrgang et al. 2011). Furthermore, the Lovelock and Houghton (2017) review of the industry highlighted the prevalence of health conditions among workers such as hypertension and diabetes, poor lung function due to high levels of smoking, and high levels of substance abuse. All of these conditions have some association with stress as lifestyle responses to mental distress (Forastieri 2016; Leka \& Jain 2010; Solar \& Irwin 2010). The 2014 NHABS (Nielsen 2015a) also lists fatigue, ill health, stress and addictions as barriers to improvement in health and safety outcomes and notes that emotional and physical stress is of high concern to those working in the industry.

Mental distress and strain are also known to have significant negative impacts on business profitability and sustainability (Leka et al. 2015; Pfeffer 2018; World Economic Forum 2008). Presenteeism (presenting for work while sick or injured) has been shown to reduce worker productivity, with a cost impact four times greater than that of directly treating the condition (Edington \& Burton 2003). The latest NHABS reported that $53 \%$ of forest workers surveyed had worked while sick or injured and $46 \%$ had worked while overtired (Nielsen 2018). Similarly, a reduction in psychological health has also been associated with the sort of risky and dangerous behaviour that can lead to both accidents and quality loss arising from adverse events (Du Plessis et al. 2013; Forastieri 2016; Leka et al. 2015). The same study that identified exposure to risks and hazards as a risk factor for mental distress also found an association between mental distress and risky and dangerous behaviour (Nahrgang et al. 2011). Finally, workers exposed to hazardous psychosocial environments are less likely to engage in re-training or further learning (Leka et al. 2015). This should be of concern to an industry looking to adapt to the physical safety risks through the introduction of mechanised harvesting systems (Steepland Harvesting Programme 2018) and increase its workforce to take advantage of growth opportunities (Harris 2017; Moore 2017).

\section{Health impacts of psychosocial workplace conditions}

Within the international forest industry there are several studies that examine the relationship between psychosocial workplace conditions and workers' health in forest and logging operations. Although none employ the psychosocial hazard framework outlined in Table 1 , all consider factors that fit within that framework. Elements such as psychological demand, intellectual discretion and exposure to risks and hazards have been associated with disorders of the neck / shoulders and lower back (Hagen et al. 1998), mental strain (Inoue 1996), and reduced job or life satisfaction (Mylek \& Schirmer 2015). The international findings fit with the work of Lilley et al. (2002) on fatigue, work / rest patterns and recent injury and near injury experience. This found that $78 \%$ of participants reported experiencing fatigue sometimes, often, or always, with $19 \%$ experiencing fatigue often or always. There was also a significant association between self-reported near misses in the previous 12 months and the reported level of fatigue experienced at work. Getting eight hours sleep and taking breaks was associated with reduced fatigue, but the majority of participants reported having seven hours or less sleep per night (and almost 25\% reported six hours or less). These are all psychosocial conditions associated with reduced mental wellbeing. Despite the paucity of research, there is enough evidence to suggest forestry workplaces contain psychosocial hazards that are harmful to mental health and that these hazards fit within the European Framework (see table 1). Research in the New Zealand forest industry (Lilley et al. 2002; Lovelock \& Houghton 2017; Nielsen 2015b) suggests these conditions also apply to local forestry workplaces.

However, some research within the forest industry highlights a key difference between physical hazards and the psychosocial domains listed as hazards in Table 1. As noted above, the risk management objective for a physical hazard is to reduce the potential of that hazard negatively impacting the health condition of the worker (Health and Safety at Work Act 2015). The goal is for 
the worker to go home at the end of the day in the same health state as when they arrived. On the other hand, effective management of psychosocial risks creates the potential for the worker to go home with enhanced wellbeing (Bentley et al. 2019; Leka et al. 2015). In their study of the impact of job content (see Table 1) on logging machine operator wellbeing, Hanse and Winkel (2008) found that daily task variety, job rotation and access to breaks when required were all positively associated with job satisfaction to a statistically significant degree. They also found a statistically significant positive association between job control and job rotation with reduced musculoskeletal symptoms, and between job rotation and access to breaks with reduced headaches and sleeping problems. Overall, job rotation - defined as operating a shift system that broke up machine operating hours, altering tasks to reduce machine operating tasks, and restricting or controlling the number of machine operating hours - had a positive impact across all three measures of wellbeing in the study.

Similarly, in their survey of Australian forestry managers and workers, Mylek and Schirmer (2015) found a number of work context elements (see Table 1) were associated with improved wellbeing. Participants who felt they had more control over their work, reported a better work-life balance and were more satisfied with their income also reported higher life satisfaction and general health. Other psychosocial conditions that were significantly associated with higher life satisfaction included job security, a positive workplace culture (defined as confidence in being able to express views), a felt level of social support, higher work efficacy and a positive work-related social identity. Interestingly, only job control, work-life balance, income, a positive culture, and work-related efficacy were positively associated with general health. What these results reflect is that psychosocial factors can be managed, not just to reduce work-related stress but to promote worker engagement, "a persistent, positive affective-motivational state of fulfilment that is characterised by the three components of vigour, dedication and absorption" (Maslach \& Leiter 2016, p. 104) as a state of wellbeing. Furthermore, Nahrgang et al. (2011) found engagement was positively associated with reductions in risky and unsafe behaviour, adverse events and accidents and injuries. If psychosocial risk management is approached with engagement as the goal, psychosocial factors can switch from hazards to be eliminated to protective factors that can be pursued, not only to protect workers from harm but also to promote wellbeing.

\section{Changing Psychosocial Conditions - from harmful to "well-ful"}

While the Health and Safety at Work Act 2015 might make it clear that any forest owner or manager must ensure, to a reasonably practicable extent, the mental and physical health of those working in the forest, the nature of their relationship with the workforce does not easily fit with the 'employee' focus of the psychosocial risk framework. A forest owner or manager could easily be forgiven for thinking that psychosocial risks exist only within the organisations and workplaces in which the workers are directly employed. That highlights a specific weakness of this approach to thinking about workrelated stress. The weakness is that the model assumes that all of the stress experience captured in the research originates within the worker's immediate work context (Theorell et al. 2015). This is of concern for the forest industry, as it ignores the broader social structures and systems (e.g. piece rate contracts) that may drive those risk factors in the immediate work context. It also overlooks the ways people exist within adjacent systems that may have highly permeable boundaries. With such a narrow view of context, the focus goes onto the individual and what can be done to enable individual coping (Harkness et al. 2005). As a result, workplace wellbeing interventions typically seek either to modify micro-organisational factors (e.g. decision latitude and social support) that surround the individual (Väänänen et al. 2014) or to enhance the individual's ability to cope through counselling or stress management techniques (Harkness et al. 2005). Macro-organisation and wider social system issues are often not addressed and the opportunity to eliminate stress through removal of the stressors in the wider context is not considered (Dewe et al. 2010).

In considering how psychosocial factors could be managed to the benefit of both individuals and the organisations in which they work, it is important to recognise that workplaces sit within an ecological system where they exist in relationship with all other parts of that ecological system. Ecological systems theories, such as that proposed by Bronfenbrenner (1977), explain human behaviour by recognising that individuals always act within these larger social and ecological systems (Figure 1). To understand behaviour it is also important to understand the nature of the institutions and social structures within each level of the system and the ways in which those levels interact and may reinforce each other (Golden \& Earp 2012). Stokols (1992) argues that the social, physical, and cultural aspects of this multilayered environment each have a cumulative effect on health. There are consequently multiple influences on specific health behaviours and outcomes, and multiple opportunities to intervene. Achieving change will require interventions at a number of different points within the system (Sallis et al. 2008). Unfortunately, interventions for worker wellbeing within the New Zealand forest industry, as guided by the legislation and the traditional conception of workplace mental health, are focused almost entirely on the specific settings in which people work. Yet what the ecological perspective shows is that health is determined as much by what goes on in the mesosystem (where those settings interact, see Figure 1) and by the social, political and cultural settings of the exo- and macrosystems, as by what goes on within the specific work setting.

The significance of this point for designing wellbeing interventions can be illustrated by considering the interactions between the various industry players. Lilley et al. (2002) confirmed that the total workday length for forestry workers in New Zealand was increasing, 


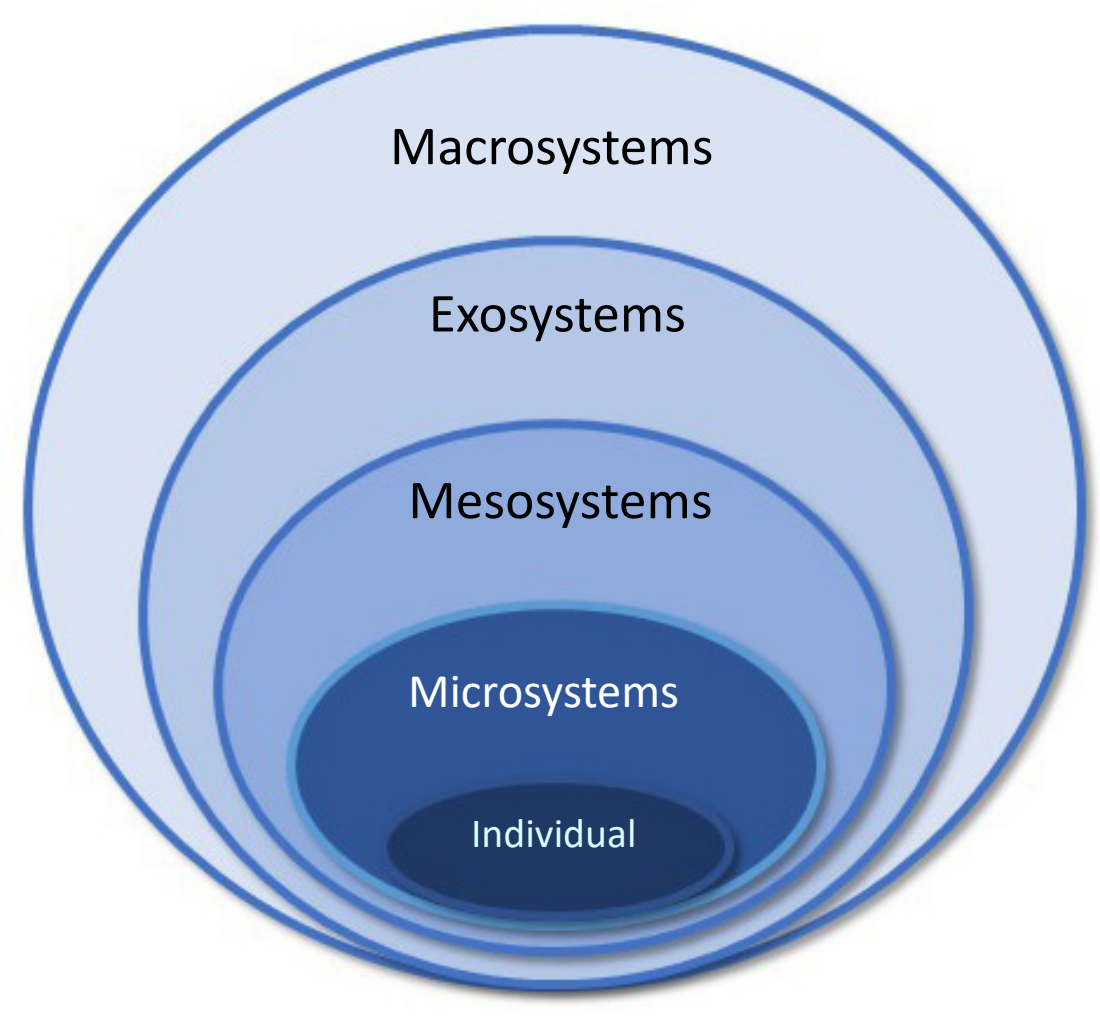

SYSTEM LEVELS

Macro - overarching institutional patterns of the culture or subculture, such as economic, social, educational, legal and political structures (e.g. hegemonic masculinity, business orthodoxy)

Exo - specific social structures that impinge upon or encompass the immediate settings in which people are found (e.g. the forest industry, WorkSafe, FISC)

Meso - interactions between the major settings an individual inhabits (e.g. specific log supply chains)

Micro - specific settings such as place, time, physical features, activity, participant, and role (e.g. specific logging crew)

FIGURE 1: Bronfennbrenner's Ecological Systems Theory (adapted from Bronfenbrenner 1977)

that there were substantial groups of workers whose break times were compromised, and that there had been a reduction in the number of workers getting two consecutive days off in every seven days in the preceding ten years. Hide et al. (2010) study of cable logging operations noted the inconsistent break times, and that work pace and workload were often driven by the pace of the adjacent workstations. These are all factors directly controllable within the workplace (the microsystem, in Bronfenbrenner's framework, see Figure 1). However, they also pointed to the impact of elements beyond the direct control of the contractor. The challenge of achieving daily piece rate targets, working on sites with limited operating and storage space, and bottlenecks in the downstream supply chain all directly impacted the working day length. These conditions arise from the mesosystem (interactions within the supply chain) and the exosystem (outsourcing operations using piece rate contracts). Furthermore, long commutes were found to increase the length of the workday, suggesting that urbanisation, a macrosystem change, was adding to the problem.

Ecological systems theory also helps explain the impact of interactions between work, family, the community, and wider societal issues such as gender and socio-economic status. Lovelock and Houghton (2017) identified that the poor health and safety outcomes in the New Zealand forest industry may originate with psychosocial stressors outside of the workplace. These included high drug use in worker families and communities, insecure and overcrowded accommodation, and conflict with unemployed family members. Studies from outside the industry have also highlighted the potential of family conflict to reduce the cognitive resources available to an employee at work (Du et al. 2017). While confirming partner conflict as a predictor of wellbeing (in this case, using burnout as the measure of wellbeing), Rössler et al. (2015) also found an association with never having been married. This suggests that it is not only what goes on in families that impacts worker performance and wellbeing (Kinnunen et al. 2006) but also the structure of the family itself.

As ecological systems theory indicates, work can also impact wellbeing within settings outside work. What appear to be unhealthy lifestyle choices (e.g. smoking, drug and alcohol use, a carbohydrate dense diet associated with obesity, diabetes and hypertension) could be, in part, a coping response to stress arising from work or from the situations workers find themselves in as a result of the way their work is organised (Forastieri 2016; Leka \& Jain 2010). Construction workers in Australia have linked several personal health issues, including an increased use of alcohol, to the pressures of long working hours (McKenzie, 2008, as cited by Du Plessis et al. 2013). Evaluations of health promotion programs within male dominated industries in Canada and Australia have also found that while workers recognise the importance of healthy lifestyle choices on their physical and mental health, they also face a number of obstacles in making those choices (Lingard \& Turner 2015; Seaton et al. 2019). Low socio-economic status, long work hours that interfere with family commitments, 
and socio-cultural constructions of masculinity that emphasise material success can contribute to a culture that inadvertently promotes unhealthy diets, alcohol misuse, and risk taking and stoicism in the face of difficulties (Du Plessis et al. 2013; Iacuone 2005; Kolmet et al. 2006; Lingard \& Turner 2015; Seaton et al. 2019). Lovelock and Houghton (2017) pointed to a similar conflict between the imposition of safety rules on New Zealand logging crews and the socio-cultural constructs operating within those crews (e.g. the role of experience in establishing crew hierarchy). Lingard and Turner (2015) concluded that the underlying environmental causes of construction workers' unhealthy behaviours may be structural and that health promotion initiatives designed to change workers' health behaviour will consequently be of limited effectiveness. This could well apply to the New Zealand forest industry.

As stated above, an ecological approach suggests that improving workers' health outcomes will require intervening in multiple places within the system (Sallis et al. 2008). Poor mental health at work will most likely reflect multiple psychosocial factors, some of which will be located outside of the direct relationship with the employee or, indeed, outside of the workplace entirely, in families, the community and society more generally (Forastieri 2016; Lingard \& Turner 2015; Sallis et al. 2008). However it is also important to recognise that benefits from successful interventions are also likely to accrue in multiple places within the system. Leka et al. (2015) argue that successful psychosocial risk management can result in benefits to organisational productivity and quality. A study of 7000 Polish machine operators using the European Framework for Psychosocial Risks set out in Table 1 highlighted the inverse relationship between the level of the psychosocial risk reported by the participants and their reported levels of commitment to and enjoyment of the work and their workplace (Mościcka-Teske et al. 2017). While the target setting for intervention may be in the forest, benefits such as improvements to productivity, quality and worker commitment will flow beyond the immediate employer to the forest owner and industry level. Similarly, psychosocial protective factors experienced at work also have the potential to spill over into the family environment through enhanced mood and skills such as time management (Kinnunen et al. 2006) or self-esteem and social support (Ten Brummelhuis \& Bakker 2012). Given this complexity, improving the psychosocial factors within forestry workplaces will mean looking beyond the day-to-day work settings and workplaces in which forest workers are engaged and considering the forest management practices and operations that impact the way work is organised and completed.

Figure 2 sets out some aspects of forest management practices that have the potential to influence the psychosocial risk factors for stress. They represent risk factors because of their potential impact on the relationship with the contractor, particularly with respect to the contractor's profitability, the balance of power within the contract and its impact on business risk. Examples of the way in which risk is transferred to the contractor, through the contract, include the setting of a production target as the basis for payment, and the forest owner / manager's engineering of the work site, particularly the quality of the access and, for harvesting, the setting layout, the maximum and average haul distances, and the skid size. Some of these elements of risk involve decisions made with information gathered for the forest owner's uses but which may not be fit for purpose for managing the contractor's risk (e.g. inventory data). Some of the key decisions may be made in the absence of data or evidence (e.g. estimating production targets without prior productivity measurement evidence). The forest owner / manager may still have control of the sources of risk despite the consequences of the risk having been handed over to the contractor (e.g. establishing piece rates using production when the payment is actually based on uplift and the trucking and delivery is directly contracted and managed by the forest owner). Elements of the forest owner's / manager's risk can be mitigated by passing some of that risk to the contractor (e.g. the need for layoffs during market downturn). Risk is also imposed on the contractor though the terms of the contract, including the crew day rate used as the basis for the piece rate and the way in which perceived transgressions against the contract conditions are dealt with (e.g. stand downs).

The allocation of risk between the forest owner / manager and their contractors can be thought of as an expression of the forest owner / manager's psychosocial safety climate. The psychosocial safety climate refers to the "shared perceptions of organisational policies, practices and procedures for the protection of worker psychological health and safety that are largely driven from senior management" (Idris et al. 2012, p. 19). The terms and conditions of the contract have a material impact on the demands made on the contractors and their workers (e.g. work pressure resulting from target or throughput) and the resources they have available to them (e.g. profitability, cashflow, skills, machinery, work study data, control over site lay out). The Job Demand Resources Model (Bakker \& Demerouti 2007) describes how work-related stress is constructed in the balancing of demands and resources. When demands outweigh resources, stress results. Being inherently motivational, resources can overcome the costs associated with demands and generate engagement. The potential for the work contained in that contract to have a positive impact on wellbeing is established, essentially, through the process of generating the relationship between the forest owner / manager and the contractor, and then capturing that relationship within the contracting processes.

Figure 2 also suggests that working directly with communities may be required to ensure interventions in the workplace are successful (Sallis et al. 2008). There is a need to engage with the workforce and their communities in a socially and culturally aligned manner (Wold \& Mittelmark 2018). The New Zealand forestry industry is dominated by men who often conform to the dominant constructs of working class masculinity in Aotearoa New Zealand, irrespective of whether 


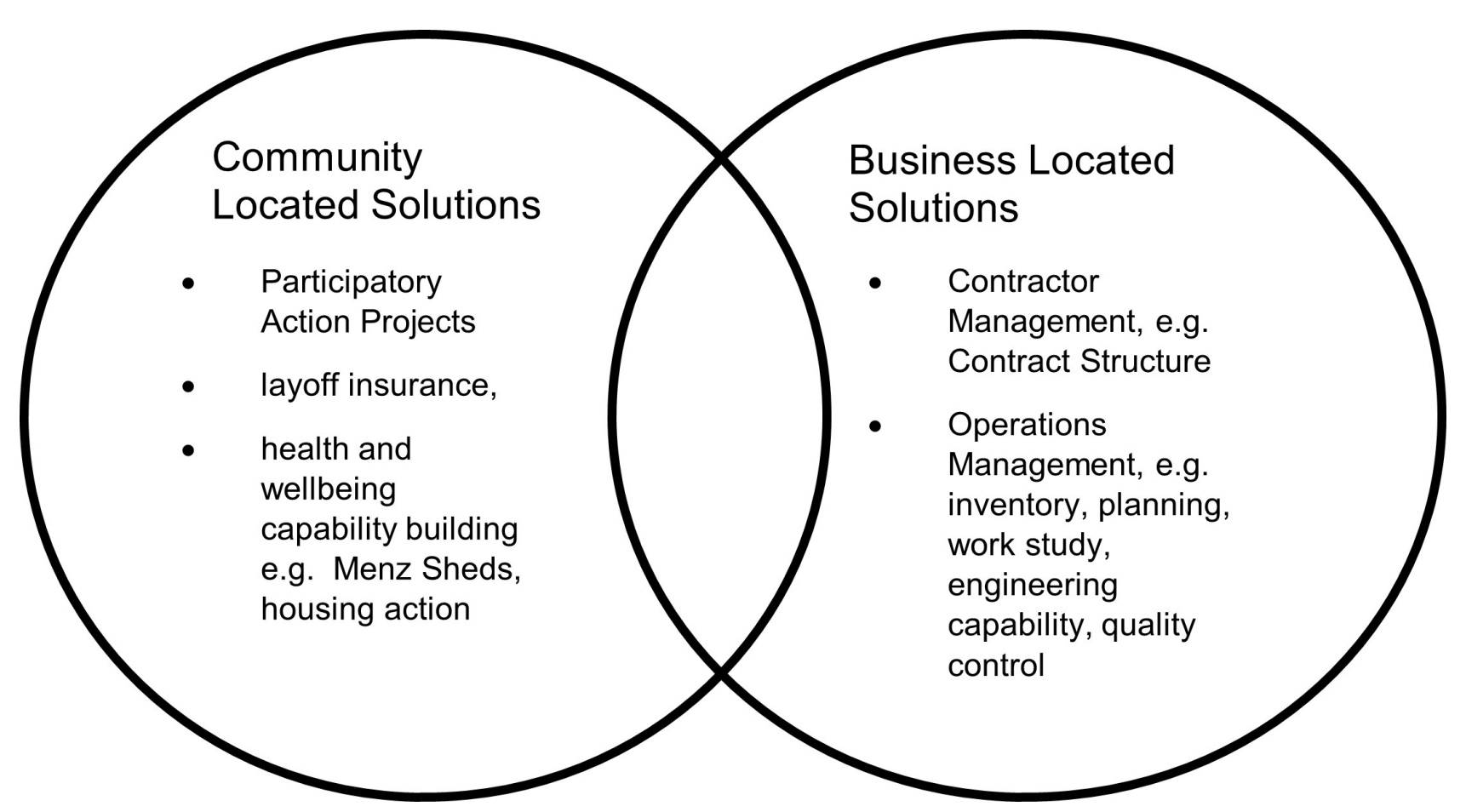

FIGURE 2: Solution Map

that helps or hinders the industry's efforts to mitigate the health risks of stress. Working with that dominant construct means involving those men in the design, decision making and implementation of any efforts to mitigate mental health risks. Fortunately, there are some good examples of successful mental health initiatives (mostly focused on suicide prevention) centred on male participant empowerment, such as the Community Response to Eliminating Suicide (CORES) programme developed in rural Tasmania (Jones et al. 2015) and the Mates in Construction initiative developed in the Queensland construction industry (Martin et al. 2016). Technology is also being used in mental health prevention and care to overcome obstacles to accessing help services (Luxton et al. 2011). It also means recognising that the community's contribution to health and wellbeing involves infrastructure and services such as housing, schools and health centres (Solar \& Irwin 2010) and that business are increasingly playing a role in the development of community capability as a community partner (Lee 2011).

\section{Implications}

If the New Zealand forest industry accepts that its workers operate in conditions that pose a mental health risk, then ecological systems theory can be used as a basis for turning that risk into an opportunity to enhance the industry's value and social licence. However, it has not been the intention of this paper to be specific about recommended interventions. While the little research that does exist about the psychosocial conditions within New Zealand's forestry workplaces suggest they can be understood through the internationally recognised frameworks, Lovelock and Houghton (2017) show that even well-intentioned initiatives such as the imposition of greater controls around safe practice can be met with resistance if they do not fit with the socio-cultural constructs in operation for this particular workforce. Socio-cultural constructs of gender have also been implicated in the resistance to making healthier eating choices by Australian construction workers (Lingard \& Turner 2015). As the research reviewed here indicates, proceeding with worker wellbeing interventions in the absence of an ecological perspective carries some risk. Further research that aims to understand what those who work in the bush perceive as their biggest threats and challenges, and what they regard as their coping resources and obstacles, is required before interventions can be prescribed with confidence.

\section{Conclusions}

This paper has summarised what the extant research can tell forest managers in New Zealand about stress and its various expressions in the workplace (where it is both a potential risk and a potential opportunity). It has assessed that risk by looking at the health and safety consequences of mental distress and by examining what is known about psychosocial hazards within forestry workplaces. It then suggested that mitigating those risks will require going beyond harm reduction as a strategy to thinking about psychosocial factors as possible drivers of a more engaged and committed workforce. Interventions aimed at taking advantage of those opportunities within forest management practice and the environments outside the workplace will require thinking beyond the contracts engaging the workforce and instead focusing 
on the risk factors inherent in forest management practice and the communities in which workers reside. The rewards for doing so go beyond compliance with health and safety legislation.

At its heart, the provision of safe and healthy work environments is a moral and ethical issue. As noted earlier, the International Labour Organisation's principles are that work should take place not only in a safe and healthy working environment but also in an environment that offers real possibilities for personal achievement, self-fulfilment and service to society (Forastieri 2016). In other words, the imperative with health and safety management is to go beyond ensuring workers survive to enabling workers to thrive. The New Zealand forest industry has an opportunity to go beyond the harm reduction focus of the current legislation through promoting worker health and wellbeing, and this should enhance both the industry's economic performance and its environmental sustainability.

\section{Competing interests}

The authors declare that they have no competing interests.

\section{Authors' contributions}

TB undertook most of the work for this manuscript, including establishing the project concept, reviewing the literature, and writing the text. The development of the project and revisions to the manuscript were extensively supported by RV and DC.

\section{Acknowledgements}

The authors wish to express their gratitude for the contributions of Keith Raymond, Harvesting Programme Leader, Forest Growers Research Ltd, and Brionny Hooper, Human Factors Scientist, Scion, who commented on an earlier version of the manuscript.

\section{Funding}

This research project that informs this article is being carried out with the financial support of Forest Growers Research Ltd, the Forest Industry Safety Council, the New Zealand Institute of Forestry, the Ministry for Primary Industries and the School of Forestry at the University of Canterbury. We gratefully acknowledge their support.

\section{References}

Ahola, K., Salminen, S., Toppinen-Tanner, S., Koskinen, A., \& Väänänen, A. (2013). Occupational burnout and severe injuries: an eight-year prospective cohort study among Finnish forest industry workers. Journal of Occupational Health, 55(6), 450-457. https://doi.org/10.1539/joh.13-0021-0A

Ahola, K., Väänänen, A., Koskinen, A., Kouvonen, A., \& Shirom, A. (2010). Burnout as a predictor of allcause mortality among industrial employees: A 10year prospective register-linkage study. Journal of
Psychosomatic Research, 69(1), 51-57. https://doi. org/10.1016/j.jpsychores.2010.01.002

Bakker, A.B., \& Demerouti, E. (2007). The Job DemandsResources model: state of the art. Journal of Managerial Psychology, 22(3), 309-328. https:// doi.org/10.1108/02683940710733115

Bentley, T., Tappin., D., Blackwood, K., Bone, K., Forsyth, D., Gardner, D., D'Souza, N., Cately, B., Port, Z., Piplani, R., Brougham, D., \& Ashby, L. (2019). The New Zealand Workplace Barometer: A report on findings from the 2018 survey of the New Zealand Workplace Barometer. Auckland, NZ: Massey University. Retrieved from https://www.massey. ac.nz/massey/fms/school of management/HWG/ The\%20NZ\%20Workplace\%20Barometer 2018 final.pdf?C6C774E163837648C1FC91CF543FC FC3

Bronfenbrenner, U. (1977). Toward an experimental ecology of human development. American Psychologist, 32(7), 513-531. https://doi. org/10.1037/0003-066X.32.7.513

Chirico, F., Heponiemi, T., Pavlova, M., Zaffina, S., \& Magnavita, N. (2019). Psychosocial Risk Prevention in a Global Occupational Health Perspective. A Descriptive Analysis. International Journal of Environmental Research and Public Health, 16(14), 2470. https://doi.org/10.3390/ijerph16142470

Coronial Services. (2020). Annual Provisional Suicide Statistics for deaths reported to the Coroner between 1 July 2007 and 30 June 2020. Wellington, NZ: Ministry of Justice. Retrieved from https://coronialservices.justice.govt.nz/ assets/Documents/Publications/2020-AnnualProvisional-Suicide-Statistics.pdf

Cox, T., Griffiths, A., \& Randall, R. (2003). A risk management approach to the prevention of work stress. In M. J. Shabracq, J. A. M. Winnubst \& C. Cooper (Eds.), The Handbook of Work and Health Psychology (2nd ed., pp. 191-208). Chichester, UK: Wiley. https://doi.org/10.1002/0470013400. ch10

Dewe, P., \& Cooper, C. (2017). Work Stress and Coping: Forces of Change and Challenges (1st ed.). London: SAGE. https://doi.org/10.4135/9781526421678

Dewe, P., O'Driscoll, M., \& Cooper, C. (2010). Coping with work stress: $A$ review and critique. Chichester, UK: Wiley-Blackwell. https://doi. org/10.1002/9780470711712

Du, D., Derks, D., \& Bakker, A.B. (2017). Daily spillover from family to work: a test of the Work-Home Resources Model. Journal of Occupational Health Psychology. https://doi.org/10.1037/ocp0000073

Du Plessis, K., Cronin, D., Corney, T., \& Green, E. (2013). Australian blue-collar men's health and well-being: contextual issues for workplace health promotion interventions. Health Promotion Practice, 14(5), 715-720. https://doi. org/10.1177/1524839912464046 
Edington, D.W., \& Burton, W.N. (2003). Health and productivity. In R. J. McCunney (Ed.), A Practical Approach to Occupational and Environmental Medicine. (3rd ed.), pp.140-152. Boston, MA, USA: Little, Brown \& Co.

Forastieri, V. (2016). Prevention of psychosocial risks and work-related stress. International Journal of Labour Research, 8(1-2), 11-34.

Forest Industry Safety Council. (2018). FISC's KYND Wellness Health Pilot. 5. Retrieved from https:// www.fisc.org.nz/uploads/6/6/2/5/66257655/ fisc_kynd_pilot_2018.pdf

Golden, S.D., \& Earp, J.A.L. (2012). Social ecological approaches to individuals and their contexts: Twenty years of health education \& behavior health promotion interventions. Health Education \& Behavior, 39(3), 364-372. https://doi. org/10.1177/1090198111418634

Hagen, K.B., Magnus, P., \& Vetlesen, K. (1998). Neck/shoulder and low-back disorders in the forestry industry: relationship to work tasks and perceived psychosocial job stress. Ergonomics, 41(10), 1510-1518. https://doi. org/10.1080/001401398186243

Hanse, J.J., \& Winkel, J. (2008). Work organisation constructs and ergonomic outcomes among European forest machine operators. Ergonomics, 51(7), 968-981. https://doi. org/10.1080/00140130801961893

Harkness, A.M.B., Long, B.C., Bermbach, N., \& Patterson, K. (2005). Talking about work stress: Discourse analysis and implications for stress interventions. Work and Stress, 19(2), 121-136. https://doi. org/10.1080/02678370500160068

Harris, C. (2017). NZ forestry industry cries out for young workers, Dominion Post. Retrieved from: https:// www.stuff.co.nz/business/industries/90013570/ skills-shortage-in-forestry-more-problematicthan-drugs-fica-says

Health and Safety at Work Act (2015). Retrieved from: $\quad$ https://www.legislation.govt.nz/act/ public/2015/0070/latest/DLM5976660.html

Hide, S.A., Tappin, D.C., \& Parker, R.J. (2010). Optimising Work Organisation for Maximum Performance. Harvesting Technical Note, 3(6). Rotorua, New Zealand: Future Forests Research. 6 p. Retrieved from: https://fgr.nz/documents/optimising-workorganisation-maximum-performance-2/

Iacuone, D. (2005). "Real Men Are Tough Guys": Hegemonic Masculinity and Safety in the Construction Industry. Journal of Men's Studies, 13(2), 247-266. https://doi.org/10.3149/ jms.1302.247

Idris, M.A., Dollard, M.F., Coward, J., \& Dormann, C. (2012). Psychosocial safety climate: Conceptual distinctiveness and effect on job demands and worker psychological health. Safety Science, 50(1),

\section{9-28.https://doi.org/10.1016/i.ssci.2011.06.005}

Inoue, K. (1996). Operators' mental strain in operating the high proficient forestry machine. Journal of Forest Research, 1(4), 195-197. https://doi. org/10.1007/BF02348324

Jones, S., Walker, C., Miles, A., De Silva, E., \& Zimitat, C. (2015). A rural, community-based suicide awareness and intervention program. Rural \& Remote Health, 15(2). https://doi.org/10.22605/ RRH2972

Kinnunen, U., Feldt, T., Geurts, S., \& Pulkkinen, L.E.A. (2006). Types of work-family interface: Wellbeing correlates of negative and positive spillover between work and family. Scandinavian Journal of Psychology, 47(2), 149-162. https://doi. org/10.1111/j.1467-9450.2006.00502.x

Kolmet, M., Mariño, R., \& Plummer, D. (2006). AngloAustralian male blue-collar workers discuss gender and health issues. International Journal of Men's Health, 5(1), 81-91. https://doi.org/10.3149/ jmh.0501.81

Lee, L. (2011). Business-community partnerships: understanding the nature of partnership. Corporate Governance: The International Journal of Business in Society, 11(1), 29-40. https://doi. org/10.1108/14720701111108826

Leka, S., \& Jain, A. (2010). Health impact of psychosocial hazards at work: an overview. Geneva: World Health Organisation. Retrieved from https://apps.who.int/iris/bitstream/ handle/10665/44428/9788393608102 pol.pdf

Leka, S., Van Wassenhove, W., \& Jain, A. (2015). Is psychosocial risk prevention possible? Deconstructing common presumptions. Safety Science, 71, 61-67. https://doi.org/10.1016/j. ssci.2014.03.014

Lilley, R., Feyer, A.-M., Kirk, P., \& Gander, P. (2002). A survey of forest workers in New Zealand: Do hours of work, rest, and recovery play a role in accidents and injury? Journal of Safety Research, 33(1), 53-71. https://doi.org/10.1016/S0022-4375(02)00003$\underline{8}$

Lingard, H., \& Turner, M. (2015). Improving the health of male, blue collar construction workers: a social ecological perspective. Construction Management \& Economics, 33(1), 18-34. https://doi.org/10.108 $\underline{0 / 01446193.2014 .997259}$

Lovelock, K., \& Houghton, R. (2017). Health on the outside, sick on the inside. Work Related Health in Forestry. Wellington, New Zealand: WorkSafe New Zealand. Retrieved from: http://www. worksafe.govt.nz/worksafe/research/researchreports/2016-forestry-research/2016-forestryresearch-documents/2016-Forestry-ResearchReport-5.pdf.

Luxton, D.D., June, J.D., \& Kinn, J.T. (2011). Technologybased suicide prevention: current applications and 
future directions. Telemedicine and e-Health, 17(1), 50-54. https://doi.org/10.1089/tmj.2010.0091

Martin, G., Swannell, S., Milner, A., \& Gullestrup, J. (2016). Mates in construction suicide prevention program: A five year review. Journal of Community Medicine \& Health Education, 6(465). https://doi. org/10.4172/2161-0711.1000465

Maslach, C., \& Leiter, M.P. (2016). Understanding the burnout experience: recent research and its implications for psychiatry. World Psychiatry, 15(2), 103-111. https://doi.org/10.1002/wps.20311

Maslach, C., \& Leiter, M.P. (2017). New insights into burnout and health care: Strategies for improving civility and alleviating burnout. Medical Teacher, 39(2), 160-163. https://doi.org/10.1080/014215 9X.2016.1248918

Ministry for Primary Industries. (2020). Human capability in the primary industries data: part one. Wellington, New Zealand: NZ Government .Retrieved from https://www.mpi.govt.nz/ dmsdocument/17638-human-capability-in-theprimary-industries-part-1-2002-to-2016-anoverview.

Modini, M., Joyce, S., Mykletun, A., Christensen, H., Bryant, R.A., Mitchell, P.B., \& Harvey, S.B. (2016). The mental health benefits of employment: Results of a systematic meta-review. Australasian Psychiatry, 24(4), 331-336. https://doi. org/10.1177/1039856215618523

Moore, R. (2017). Forestry worker shortage, youths sought out, The Southland Times. Retrieved from https://www.stuff.co.nz/southland-times/ news/95190310/Forestry-worker-shortageyouths-sought-out

Mościcka-Teske, A., Sadłowska-Wrzesińska, J., Butlewski, M., Misztal, A., \& Jacukowicz, A. (2017). Stressful work characteristics, health indicators and work behavior: the case of machine operators. International Journal of Occupational Safety and Ergonomics, 23(4), 510. https://doi.org/10.1080/ $\underline{10803548.2016 .1197577}$

Mylek, M.R., \& Schirmer, J. (2015). Beyond physical health and safety: supporting the wellbeing of workers employed in the forest industry. Forestry: An International Journal of Forest Research, 88(4), 391-406. https://doi.org/10.1093/forestry/ cpv011

Nahrgang, J.D., Morgeson, F.P., \& Hofmann, D.A. (2011). Safety at work: a meta-analytic investigation of the link between job demands, job resources, burnout, engagement, and safety outcomes. Journal of Applied Psychology, 96(1), 73-94. https://doi. org/10.1037/a0021484

Nielsen. (2015a). Health and safety attitudes and behaviours in the New Zealand workforce. A survey of workers and employers. 2014 baseline survey. Forestry report. Wellington, New Zealand. Retrieved from http://www.worksafe.govt.nz/ worksafe/research/research-reports/reports/ attitudes-and-behaviours-survey-baselineforestry-report.pdf

Nielsen. (2015b). Health and safety attitudes and behaviours in the New Zealand workforce: A study of workers and employers. 2014 Qualitative Research. Forestry report. (A report for WorkSafe New Zealand). Wellington, New Zealand. Retrieved from http://www.worksafe.govt.nz/worksafe/ research/research-reports/reports/attitudesand-behaviours-survey-qualitative-forestryreport.pdf

Nielsen. (2018). Health and safety attitudes and behaviours survey. Worker engagement and participation report 2017. (A report for WorkSafe New Zealand). Wellington, New Zealand. Retrieved from https://worksafe.govt.nz/research/ attitudes-and-behaviours-survey-2017/

Pearce, J., Tisch, C., \& Barnett, R. (2008). Havegeographical inequalities in cause-specific mortality in New Zealand increased during the period 1980-2001? New Zealand Medical Journal, 121(1281).

Pfeffer, J. (2018). Dying for a paycheck: How modern management harms employee health and company performance - and what we can do about it. New York: Harper Collins.

Rössler, W., Hengartner, M.P., Ajdacic-Gross, V., \& Angst, J. (2015). Predictors of burnout: Results from a prospective community study. European Archives of Psychiatry and Clinical Neuroscience, 265(1), 1925. https://doi.org/10.1007/s00406-014-0512-x

Sallis, J.F., Owen, N., \& Fisher, E.B. (2008). Ecological models of health behaviour. In K. Glanz, B. K. Rimer \& K. Viswanath (Eds.), Health Behavior and Health Education: Theory, Research, and Practice (pp. 465486). Hoboken, USA: Wiley.

Seaton, C.L., Bottorff, J.L., Oliffe, J.L., Medhurst, K., \& DeLeenheer, D. (2019). Mental health promotion in male-dominated workplaces: Perspectives of male employees and workplace representatives. Psychology of Men \& Masculinities, 20(4), 541-552. https://doi.org/10.1037/men0000182

Seidler, A., Thinschmidt, M., Deckert, S., Then, F., Hegewald, J., Nieuwenhuijsen, K., \& Riedel-Heller, S.G. (2014). The role of psychosocial working conditions on burnout and its core component emotional exhaustion - a systematic review. Journal of Occupational Medicine and Toxicology, $9(1), 10$. https://doi.org/10.1186/1745-6673-9$\underline{10}$

Solar, O., \& Irwin, A. (2010). A conceptual framework for action on the social determinants of health. Social Determinants of Health Discussion Paper 2 (Policy and Practice). Geneva: World Health Organisation. Retrieved from https://apps.who.int/iris/rest/ bitstreams/52952/retrieve

Steepland Harvesting Programme. (2018). Steepland Harvesting Programme Post-Programme Report 
2018. Rotorua, NZ. Retrieved from https://fgr.nz/ documents/download/7206?999267066

Stokols, D.S. (1992). Establishing and maintaining healthy environments: Toward a social ecology of health promotion. American Psychologist, 47(1), 6-22. https://doi.org/10.1037/0003-066X.47.1.6

Suicide Mortality Review Committee. (2016). Ngā Rāhui Hau Kura: Suicide Mortality Review Committee Feasibility Study 2014-15. Report to the Ministry of Health, 31 May 2016. Wellington, NZ: Health Quality \& Safety Commission. Retrieved from https:// www.hqsc.govt.nz/our-programmes/mrc/sumrc/ publications-and-resources/publication/2471/

Tehrani, N. (2004). Workplace trauma: Concepts, assessment and interventions: London: Brunner-Routledge. https://doi. org/10.4324/9780203500620

Ten Brummelhuis, L.L., \& Bakker, A.B. (2012). A resource perspective on the work-home interface: The work-home resources model. American Psychologist, 67(7), 545-556. https://doi. org/10.1037/a0027974

Theorell, T., Hammarström, A., Aronsson, G., Träskman Bendz, L., Grape, T., Hogstedt, C., Marteinsdottir, I., Skoog, I., \& Hall, C. (2015). A systematic review including meta-analysis of work environment and depressive symptoms. BMC Public Health, 15: 738, 14 p. https://doi.org/10.1186/s12889-015-1954$\underline{4}$

Toppinen-Tanner, S., Ahola, K., Koskinen, A., \& Väänänen, A. (2009). Burnout predicts hospitalization for mental and cardiovascular disorders: 10-year prospective results from industrial sector. Stress \& Health: Journal of the International Society for the Investigation of Stress, 25(4), 287-296. https://doi. org/10.1002/smi.1282

Toppinen-Tanner, S., Ojajärvi, A., Väänänen, A., Kalimo, R., \& Jäppinen, P. (2005). Burnout as a predictor of medically certified sick-leave absences and their diagnosed causes. Behavioral Medicine, 31(1), 1827. https://doi.org/10.3200/BMED.31.1.18-32

Toppinen-Tanner, S., Kalimo, R., \& Mutanen, P. (2002). The process of burnout in white-collar and blue-collar jobs: eight-year prospective study of exhaustion. Journal of Organizational Behavior, 23(5), 555-570. https://doi.org/10.1002/job.155

Väänänen, A., Koskinen, A., Joensuu, M., Kivimäki, M., Vahtera, J., Kouvonen, A., \& Jäppinen, P. (2008). Lack of predictability at work and risk of acute myocardial infarction: An 18-year prospective study of industrial employees. American Journal of Public Health, 98(12), 2264-2271. https://doi. org/10.2105/AJPH.2007.122382

Väänänen, A., Murray, M., \& Kuokkanen, A. (2014). The growth and stagnation of work stress: Publication trends and scientific representations 1960-2011. History of the Human Sciences, 27(4), 116-138. https://doi.org/10.1177/0952695114525168
Wold, B., \& Mittelmark, M.B. (2018). Health-promotion research over three decades: The social-ecological model and challenges in implementation of interventions. Scandinavian Journal of Public Health, 46(20_suppl), 20-26. https://doi. org/10.1177/1403494817743893

Woodward, K. (2015). Psychosocial studies: An introduction. New York, USA: Taylor \& Francis. https://doi.org/10.4324/9781315867823

World Economic Forum. (2008). Working towards wellness: The business rationale. Geneva. Retrieved from https://www.pwc.pl/en/publikacje/ business rationale.pdf

World Health Organisation. (2008). PRIMA-EF Guidance on the European Framework for Psychosocial Risk Management: A resource for employers and workers representatives. Geneva. Retrieved from http:// www.prima-ef.org/uploads/1/1/0/2/11022736/ prima-ef brochure english.pdf

World Health Organisation. (2019). Constitution of the World Health Organisation. Retrieved from https:// www.who.int/about/who-we-are/constitution 